\section{Glycoengineering of Therapeutic Antibodies}

\author{
C. Klein ${ }^{1}$ \\ ${ }^{1}$ Expert Scientist, Roche Glycart AG, Schlieren/Switzerland
}

Antibody dependent cellular cytotoxicity (ADCC) is the process of lysis of (tumor) target cells by immune effector cells. It requires the simultaneous binding of an antibody to a cell surface receptor on the target cell and via the Fc region of the antibody to the FcgRIIIa receptor on immune effector cells such as NK cells or macrophages/monocytes. Binding of the antibody to target and immune effector cells results in the cross-linking of FcgRIIla with subsequent activation of FcgRIIla signaling and release of proteins mediating the killing of the target cells such as perforin and of proteases such as granzymes. ADCC has been established as an important mode of action of therapeutic antibodies such as rituximab/ MabThera (targeting CD20), cetuximab/Erbitux (targeting EGFR) and trastuzumab/Herceptin (targeting HER2) which are approved for the treatment of various cancers. Translational research on rituximab and cetuximab has established that the response to therapeutic antibodies in patients can be influenced by the FcgRIIIa-158V/F polymorphism. This polymorphism results in the expression of a high affinity FcgRIIIa receptor ( $158 \mathrm{~V}$ ) and a low affinity FcgRIIIa receptor (158F) on immune effector cells and impacts the capability of antibodies to mediate ADCC [1-7]. We have recently developed a so-called GlycoMab technology that enhances the affinity of therapeutic antibodies for both the high and low affinity FcgRIIIa receptors through the introduction of a bisecting $\mathrm{N}$-acetyl-glucosamine residue in the carbohydrate chain of the Fc region of the antibodies. The introduction of this bisecting $\mathrm{N}$-acetyl-glucosamine moiety in the carbohydrate chain results in a steric interference with core fucosylation of the carbohydrate. This process and other approaches resulting in the afucosylation of therapeutic antibodies are known as "antibody glycoengineering". We and others have demonstrated that glycoengineering and lack of the core fucose residue results in an up to 50-fold enhanced affinity of human IgG1 antibodies for the human FcgRIIla receptors, and this subsequently results in an up to 100-fold enhanced ADCC induction (potency). Recently, we have demonstrated the structural basis of the enhanced affinity of afucosylated Fc regions for FcgRIIIa by X-ray crystallography. These studies provide a structural explanation for the high affinity and FcgRIIla specificity of glycoengineering as opposed to other technologies used for Fc-engineering such as the introduction of mutations in the Fc region that also affect binding to other FcgRs [8 -15]. Roche is currently investigating three therapeutic glycoengineered antibodies with optimized immune effector function targeting CD20, EGFR and HER3 in different phases of clinical trials. Obinutuzumab (GA101, RG7159) is a type II, anti-CD20 GlycoMab monoclonal antibody that was designed to mediate enhanced direct and immune effector cell-mediated cell killing as compared to rituximab. In addition to enhanced ADCC, due to its type II characteristics, GA101 exhibits en- hanced direct cell death induction with a concomitant reduction of CDC. In NHL animal models GA101 demonstrated a superior efficacy in terms of tumor growth inhibition and survival compared to type I CD20 antibodies such as rituximab and ofatumumab, including the induction of complete tumor remission. In non-human primates GA101 induces superior and profound $\mathrm{B}$ cell depletion in lymphoid tissues compared to rituximab. In Phase I/II clinical trials GA101 showed promising activity in heavily pretreated NHL patients. GA101 is currently being investigated in pivotal clinical trials in B-CLL, iNHL and DLBCL in combination with chemotherapy, head-to-head with rituximab-based regimens and in Rituximab-refractory iNHL as well as in various Phase II clinical trials. GA101 was the first glyco- and Fc-engineered antibody to enter clinical trials and is now the most advanced glyco- and Fc-engineered antibody in clinical trials in the world [16-24].

GA201 (RG7160) is a second anti-EGFR GlycoMab monoclonal antibody that is currently being investigated in Phase II clinical trials. It was designed to combine potent EGFR signaling inhibition with enhanced ADCC induction. In xenograft models GA201 demonstrated superior activity compared to cetuximab and panitumumab. Hence, GA201 has the potential to show clinical activity in patients with solid tumors. Phase I clinical testing in heavily pretreated patients with advanced solid tumors demonstrated a manageable toxicity profile. Evidence of anti-tumor activity was also seen, especially in patients with colorectal cancer, including a number of patients who had previously received cetuximab and/or panitumumab (1 CR, 2 PR). Interestingly, one of the partial responses was reported in a tumor-harboring a k-ras mutation. GA201 is currently undergoing Phase II clinical trials in CRC and NSCLC in combination with chemotherapy as well as a neo-adjuvant biomarker study in HNSCC [25].

Conflict of Interest: The author is employed by Roche Glycart AG.

References

1 Wang SY, Weiner G. Complement and cellular cytotoxicity in antibody therapy of cancer. Expert Opin Biol Ther 2008; 8: 759-768

2 Cartron G, Trappe RU, Solal-Celigny P et al. Interindividual variability of response to rituximab: from biological origins to individualized therapies. Clin Cancer Res 2011; 17: 19-30

3 Cartron G. FCGR3A polymorphism story: a new piece of the puzzle. Leuk Lymphoma 2009; 50: 1401 - 1402

4 Dall'Ozzo S, Tartas S, Paintaud G et al. Rituximab-dependent cytotoxicity by natural killer cells: influence of FCGR3A polymorphism on the concentration-effect relationship. Cancer Res 2004; 64: 4664-4669

5 Cartron G, Watier H, Golay J et al. From the bench to the bedside: ways to improve rituximab efficacy. Blood 2004; 104: 2635-2642

6 Cartron G, Dacheux L, Salles G et al. Therapeutic activity of humanized anti-CD20 monoclonal antibody and polymorphism in IgG Fc receptor FcgammaRIIIa gene. Blood 2002; 99: 754-758

7 Weiner LM, Surana R, Wang S. Monoclonal antibodies: versatile platforms for cancer immunotherapy. Nat Rev Immunol 2010; 10: $317-327$

8 Ferrara C, Grau S, Jager C et al. Unique carbohydrate-carbohydrate interactions are required for high affinity binding between FcgammaRIII and antibodies lacking core fucose. Proc Natl Acad Sci U S A 2011; 108: $12669-12674$

9 Ferrara C, Brunker P, Suter T et al. Modulation of therapeutic antibody effector functions by glycosylation engineering: influence of Golgi enzyme localization domain and co-expression of heterologous beta1, 4- 
$\mathrm{N}$-acetylglucosaminyltransferase III and Golgi alpha-mannosidase II. Biotechnol Bioeng 2006; 93: 851-861

10 Ferrara C, Stuart F, Sondermann P et al. The carbohydrate at FcgammaRIIIa Asn-162. An element required for high affinity binding to non-fucosylated IgG glycoforms. J Biol Chem 2006; 281: 5032 - 5036

11 Schuster M, Umana P, Ferrara C et al. Improved effector functions of a therapeutic monoclonal Lewis Y-specific antibody by glycoform engineering. Cancer Res 2005; 65: 7934-7341

12 Ashraf SQ Umana P, Mossner E et al. Humanised IgG1 antibody variants targeting membrane-bound carcinoembryonic antigen by antibodydependent cellular cytotoxicity and phagocytosis. Br J Cancer 2009; 101: $1758-1768$

13 Umana P, Jean-Mairet J, Moudry R et al. Engineered glycoforms of an antineuroblastoma IgG1 with optimized antibody-dependent cellular cytotoxic activity. Nat Biotechnol 1999; 17: 176-180

14 Yamane-Ohnuki N, Satoh M. Production of therapeutic antibodies with controlled fucosylation. MAbs 2009; 1: 230 - 236

15 Mori K, Iida S, Yamane-Ohnuki $N$ et al. Non-fucosylated therapeutic antibodies: the next generation of therapeutic antibodies. Cytotechnology 2007; 55: 109-114

16 Honeychurch J, Alduaij W, Azizyan $M$ et al. Antibody-induced nonapoptotic cell death in human lymphoma and leukemia cells is mediated through a novel reactive oxygen species dependent pathway. Blood 2012

17 Jak M, van Bochove GG, Reits EA et al. CD40 stimulation sensitizes CLL cells to lysosomal cell death induction by type II anti-CD20 mAb GA101. Blood 2011; 118: 5178-5188

18 Niederfellner G, Lammens A, Mundigl O et al. Epitope characterization and crystal structure of GA101 provide insights into the molecular basis for type I/II distinction of CD20 antibodies. Blood 2011; 118 : $358-367$

19 Alduaij W, Ivanov A, Honeychurch J et al. Novel type II anti-CD20 monoclonal antibody (GA101) evokes homotypic adhesion and actin-dependent, lysosome-mediated cell death in B-cell malignancies. Blood 2011; 117: 4519-4529

20 Bologna L, Gotti E, Manganini M et al. Mechanism of action of type II, glycoengineered, anti-CD20 monoclonal antibody GA101 in B-chronic lymphocytic leukemia whole blood assays in comparison with rituximab and alemtuzumab. J Immunol 2011; 186: 3762 - 3769

21 Dalle S, Reslan L, Besseyre de Horts $T$ et al. Preclinical studies on the mechanism of action and the anti-lymphoma activity of the novel anti-CD20 antibody GA101. Mol Cancer Ther 2011; 10: 178-185

22 Patz $M$, Isaeva P, Forcob $N$ et al. Comparison of the in vitro effects of the anti-CD20 antibodies rituximab and GA101 on chronic lymphocytic leukaemia cells. Br J Haematol 2011; 152: 295 - 306

23 Pievani A, Belussi C, Klein C et al. Enhanced killing of human B-cell lymphoma targets by combined use of cytokine-induced killer cell (CIK) cultures and anti-CD20 antibodies. Blood 2011; 117: 510-518

24 Mossner E, Brunker P, Moser S et al. Increasing the efficacy of CD20 antibody therapy through the engineering of a new type II anti-CD20 antibody with enhanced direct and immune effector cell-mediated B-cell cytotoxicity. Blood 2010; 115: $4393-4402$

25 Paz-Ares LG, Gomez-Roca C, Delord JP et al. Phase I pharmacokinetic and pharmacodynamic dose-escalation study of RG7160 (GA201), the first glycoengineered monoclonal antibody against the epidermal growth factor receptor, in patients with advanced solid tumors. J Clin Oncol 2011; 29: $3783-3790$

Bibliography

DOI http://dx.doi.org/10.1055/s-0032-1324900

Arzneimittelforschung 2012; 62, Suppl. 1: S4-S5

(c) Georg Thieme Verlag KG Stuttgart · New York .

ISSN 0004-4172

Please note that the print version was published with a different, incorrect DOI. The correct DOI is the one shown here. 